\title{
Utilization of solar energy potential on roofs: building extraction from the LiDAR database in a Hungarian sample area
}

\author{
G. Szabó ${ }^{1}$, Gy. Szabó ${ }^{2}$ P. Enyedi ${ }^{3}$ I. Fazekas ${ }^{2}$, T. Buday ${ }^{4}$, \\ A. Kerényi ${ }^{2}$, M. Paládi ${ }^{2}$, N. Mecser ${ }^{1} \&$ Sz. Szabó ${ }^{1}$ \\ ${ }^{1}$ Department of Physical Geography and Geoinformatics, \\ University of Debrecen, Hungary \\ ${ }^{2}$ Department of Landscape Protection and \\ Environmental Geography, University of Debrecen, Hungary \\ ${ }^{3}$ Research Institute of Remote Sensing and Rural Development, \\ Karoly Robert University College, Hungary \\ ${ }^{4}$ Department of Mineralogy and Geology, \\ University of Debrecen, Hungary
}

\begin{abstract}
According to the Horizon 2020 climate and energy package, legislation has to meet the 20-20-20 target. That means that EU member countries have to reduce the amount of greenhouse gases by $20 \%$ to increase the proportion of renewable energy to $20 \%$ and to improve the energy efficiency by $20 \%$. Our study is connected to renewable energy issues, the goal was to assess the extent of solar radiation exploitation potential of roofs in a typical Hungarian residential area. Our sample area $\left(\sim 1 \mathrm{~km}^{2}\right)$ was in Debrecen, the second largest city in Hungary. An aerial Light Detection and Ranging (LiDAR) survey was conducted with the density of 10 points $/ \mathrm{m}^{2}$. We extracted the buildings with the MicroStation TerraScan software and tested the geometry of them. The classification and vectorization of buildings were based on Terrascan semi-automatic algorithms in a Microstation environment. Primarily the roofs were important for us as these surfaces are the possible spaces for thermal and photovoltaic equipment. We determined the slope and aspect for each roof element and summarized the whole possible surface using the detected roof parts. Our research shows that the LiDAR-
\end{abstract}


based survey of roof-exploitation for solar energy can be a good solution in a residential area, but we have to take into account some circumstances, e.g. the corrupted roof-geometries or numerous misinterpreted street furniture.

Keywords: solar energy potential, LiDAR, roof extraction.

\section{Introduction}

Usage of renewable energy resources is the new goal of the EU's $8^{\text {th }}$ Framework Programme, the Horizon 2020 [1]. Accordingly, EU member countries should reach $20 \%$ of greenhouse gas reduction, $20 \%$ of surplus in the usage of renewable energy and $20 \%$ increase in the energy efficiency.

While the energy demand of residential areas increases drastically, transportation of energy requires very complex logistic background. The issue of local energy production in densely built-up areas has been on the agenda for a long time. Considering renewable energy resources (among others) solar energy would be suitable for the task as the devices can be installed and operated at relatively low costs. Furthermore, the produced energy can be either utilized locally or transported automatically to other networks without disturbing the daily routine of residents.

Efficiency, however, is an important condition of utilizing solar energy, i.e. its installation is worthy only in regions where insolation is appropriate. Apart from meteorological conditions, the geographical bases of insolation have to be known as well, i.e. the potential surface for solar energy utilization in a given settlement.

Regarding a settlement, roofs represent the largest surface that are generally unutilized and might be suitable for energy production. Surveying the roof spaces of a whole settlement and assessing them based on solar energy utilization (e.g. orientation, angle, and size) are time consuming.

LiDAR (Light Detection and Ranging) is an effective tool to produce highly detailed digital elevation models $[2,3]$ or to extract different parts of the surface, such as trees $[4,5]$, or urban environment [6].

Numerous publications consider the detection of buildings based on LiDAR. In the research of $\mathrm{Yu}$ et al. [7] the accurate detection of city buildings was the aim just like in the case of Zhou and Neumann [8]. Filtering buildings was also the goal in the works of Mongus et al. [9] and Li et al. [10]. In the research of Alexander et al. [11] detection of the structure of roofs received major focus. Lukac et al. [12] studied the potentially usable solar radiation of built-up areas using LiDAR data as source data for this.

Our aim was to study the suitability of using the point cloud of an aerial LiDAR survey as data source in the case of a town for filtering automatically the roofs of the building. Furthermore, we determined the roof parts where the installation of solar panels is potentially feasible using existing GIS software modules. Efficiency of particular photovoltaic panels was also calculated from potential irradiance. 


\section{Material and methods}

The selected study area is located in the northern part of Debrecen city, in eastern Hungary (Figure 1). The size of the area is $1.1 \mathrm{~km}^{2}$ built-up with one- and twostorey family houses together with four- and ten-storey buildings. Public houses, mostly educational institutes (kindergarten, school, university) are found within the area as well.

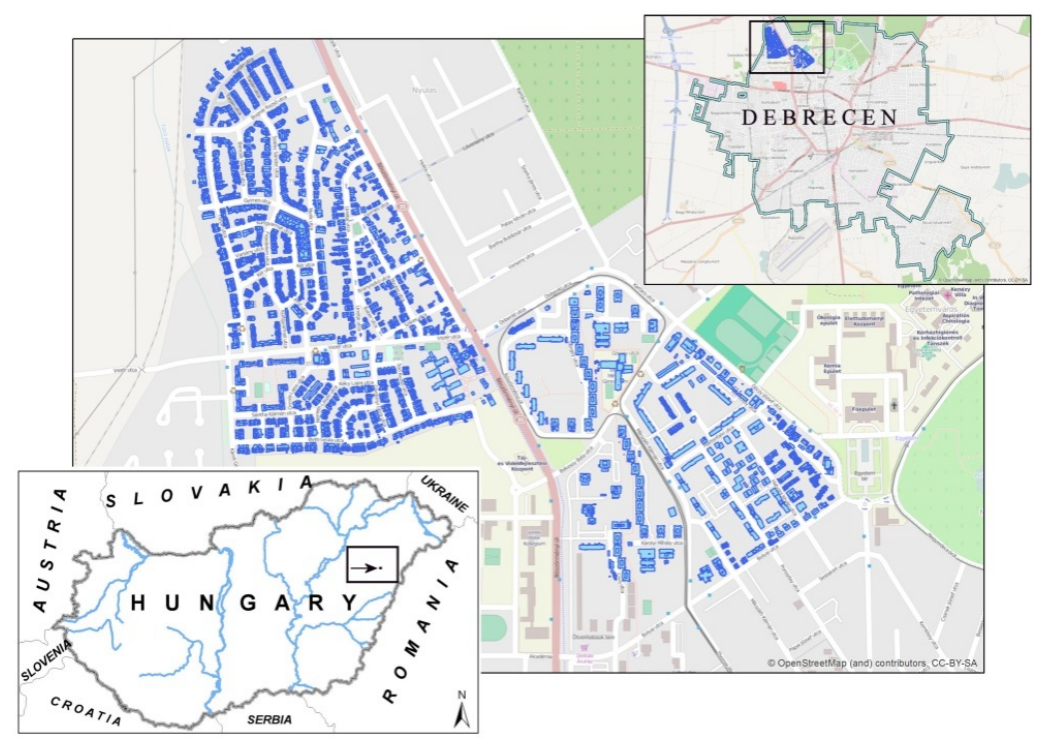

Figure 1: Location of the study area.

An aerial LiDAR survey was carried out, and the produced point cloud was our primary database (see Table 1 for specific details of the survey).

Table 1: The main specifications of the applied LiDAR system.

\begin{tabular}{|l|c|}
\hline LiDAR system specifications & Leica ALS70-HP, RCD30 \\
\hline Flight height & $1000 \mathrm{~m}$ \\
\hline Swath & $780 \mathrm{~m}$ \\
\hline Flight speed & $185 \mathrm{~km} / \mathrm{h}$ \\
\hline FOV & $43^{\circ}$ \\
\hline Pulse rate & $490 \mathrm{kHz}$ \\
\hline Dense of points & $12 \mathrm{point} / \mathrm{m}^{2}$ \\
\hline Overlap & $20 \%$ \\
\hline Scan pattern & Sinusoid \\
\hline Ortho GSD & $10 \mathrm{~cm}$ \\
\hline Number of bands & $4(\mathrm{RGBN})$ \\
\hline
\end{tabular}

Frequency of the points enabled the recognition of the characteristic building types visually based on the cross sections constructed from the point cloud (Figure 2). 


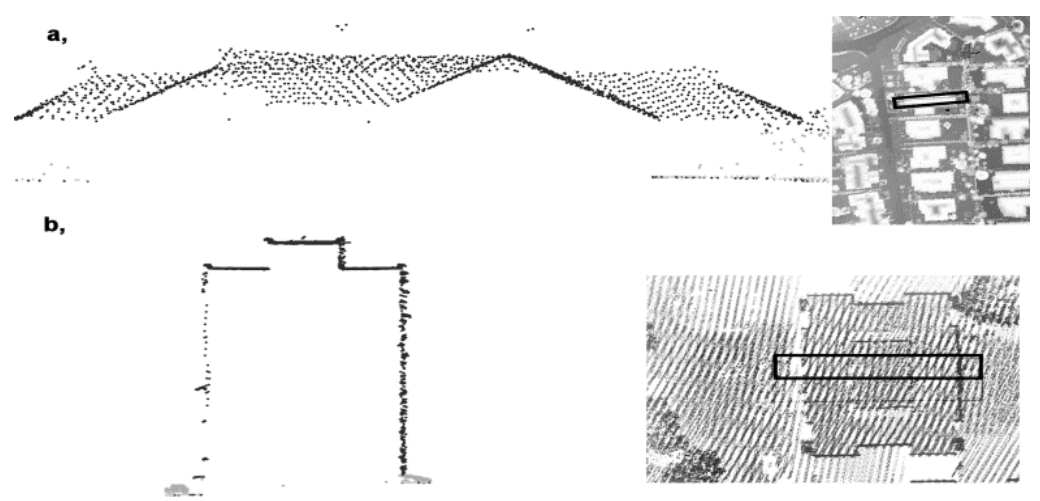

Figure 2: Characteristic building types in the LiDAR point cloud.

Certain plain parts of the roofs were obtained from the LiDAR database using the MicroStation (Bentley) TerraScan software [13] (Figure 3). Resolution of the rasterized surface model was set to $25 \mathrm{~cm}$ that is the largest possible resolution from the 12 points $/ \mathrm{m}^{2}$ LiDAR point cloud.
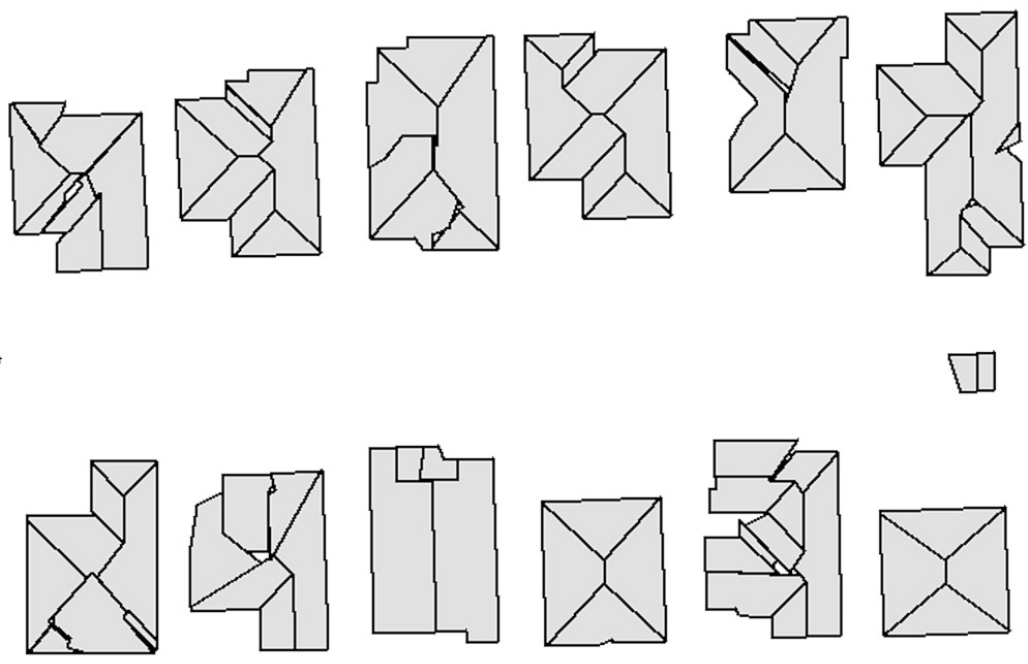

Figure 3: Roofs generated automatically in a part of the study area.

Classification of the point cloud was carried out in MicroStation's TerraScan module. We applied multiple-grade TIN building to separate the ground points, then we removed the vertical outlying points using filters. Next step was to filter out the buildings with the help of TerraScan parameterized algorithms. Afterwards, we applied a semi-automated roof-selection, extracting the vector 
features of the buildings based on the filtered points. Though, aerial images provided possibility to refine the edges of building objects, we passed it, because our goal was to generate building models automatically, with the less manual work, and to show the possibilities of the fully- or semi-automatic building extraction. During the procedure of vectorization we tended to set optimal parameters of the minimal roof-part size to reach the most accurate and detailed building models.

Our study area was located at $47^{\circ} \mathrm{N}$; therefore, we take into account roofs with an angle of $20^{\circ}-60^{\circ}$. These sloping planes were selected by an automatic procedure in ArcGIS 10 software. Orientation of the roofs was also important: roof parts were selected with the orientation with $140^{\circ}-220^{\circ}$ azimuth, i.e. optimal insolation. A photovoltaic panel with the average size of $1.7 \mathrm{~m} \mathrm{x} 1 \mathrm{~m}$ has to be installed on a roof with at least the same size to guarantee stable fixing (especially against strong wind). Therefore, roof surfaces greater than $2 \mathrm{~m}^{2}$ were selected. Long and narrow surfaces of certain buildings were also omitted as they are unsuitable for holding the panels. These were identified by calculating the compactness of the roof polygons. Generally flat roofs are utilized as well with the help of traverse system therefore, we investigated how the roofs of multi-storey buildings and flat-top public institutions would increase the potential area.

Highly important aspect was the automated character of the systems in the case of all of the above steps. This, of course, may cause errors, but our aim was to investigate the way of giving solar energy potential quickly and efficiently for a greater area (for example a whole city).

Solar energy potential for particular roofs or roof parts was calculated using the Area Solar Radiation module of ArcGIS 10. This considered diffuse and global radiation besides direct radiation at given latitude [14]. The result was obtained in $\mathrm{Wh} / \mathrm{m}^{2}$.

The accuracy of the building database calculated based on the LiDAR database was also investigated. For this the Kappa Index of Agreement (KIA) was used that showed the grade of similarity between the two databases (beyond accidental similarities) [15]. Its value ranged between 0 and 1 where 0 meant accidental similarities and 1 meant complete similarity.

\section{Results}

Control of the automatic detection of roofs was based on the official survey maps (Figure 4).

According to our experience the two databases showed good correlation. Detected differences had two sources:

- In the case of most of the buildings, the eaves caused differences as the size of the detected roofs is greater than the simple ground projection of the buildings; therefore roofs area was larger. In our case this did not cause any problem as we need the real size of the roofs.

- Demolition, construction of modification of buildings take time to be incorporated into the official database; therefore, certain detected roofs did not appeared in the control database. 


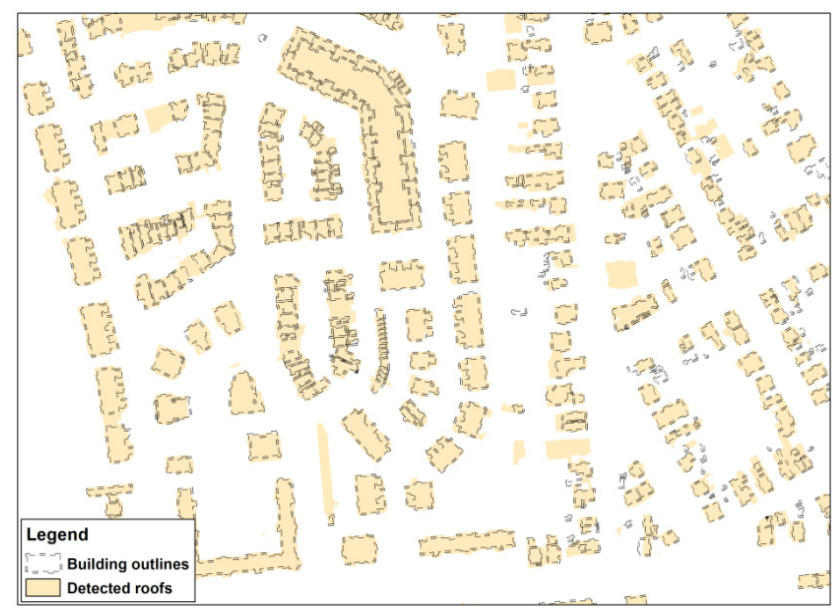

Figure 4: Comparison of roofs detected automatically and the official survey database.

Based on the comparison of LiDAR based roofs and the control database, KIA was 0.94 . Since some buildings were missing from the official geodetic survey, the difference could be further reduced, so that it can be stated that the roofs obtained from the LiDAR data reflected well the real conditions.

In total, $277700 \mathrm{~m}^{2}$ of roofs can be found in the studied area. $33700 \mathrm{~m}^{2}$ of which met the requirements (suitable orientation, angle and size) for placing photovoltaic panels on them. With the help of traverse system panels can be placed on flat roofs as well: considering these roofs (with an angle of less than $3^{\circ}$ with the horizontal) the potential area increased to $123^{\prime} 555 \mathrm{~m}^{2}$.

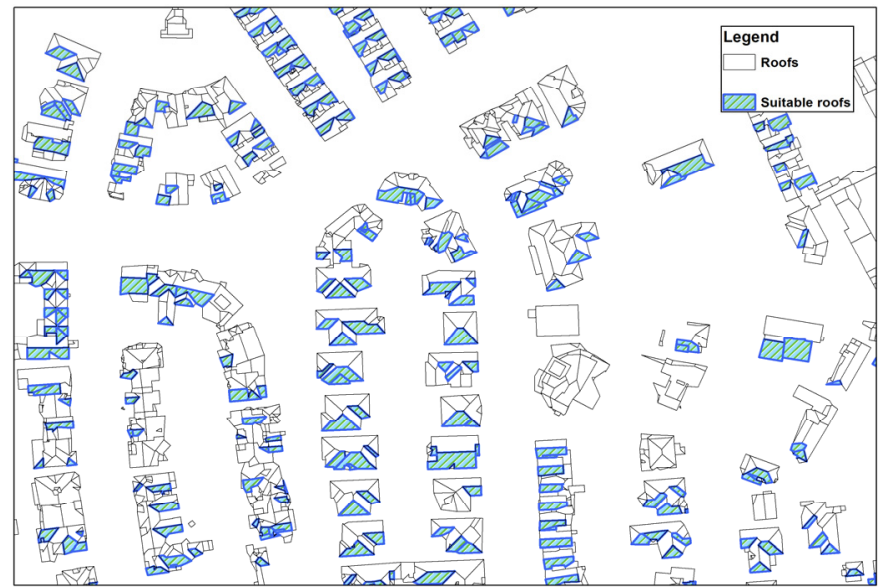

Figure 5: $\quad$ Suitable roofs for the installation of photovoltaic panels in a certain part of the study area. 
On average $6544 \mathrm{KWh}$ energy arrives on every square metre of the roofs of the study area over one year (the incoming energy in a $\mathrm{m}^{2}$ multiplied by the area of the suitable roofs). Orientation influenced this value significantly: northern roofs received an average energy value of $476.4 \mathrm{KWh} / \mathrm{m}^{2}$ while in the case of southern roofs this value was $802.4 \mathrm{KWh} / \mathrm{m}^{2}$. Values of incoming energy according to the aspect obviously varies, but the main question is the rate of the return of the investment: is it possible to produce enough energy or not (Figure 6).

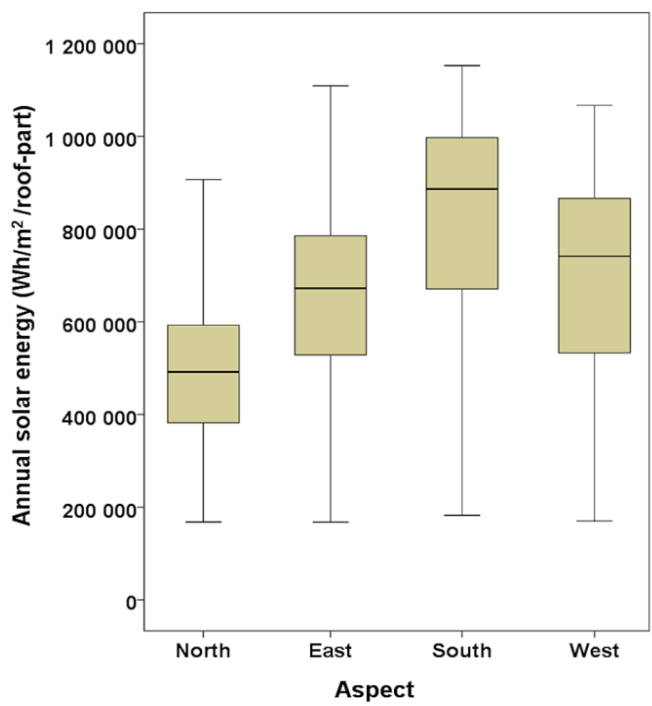

Figure 6: Distribution of specific solar energy on the roofs according to the points of the compass.

The relation between the average values of insolation of the two most differing roof orientations. Based on the Mann-Whitney $U$ test $(U=1291847.5, p<0.001$, $\mathrm{Md}_{\text {north }}=498702, \mathrm{Md}_{\text {south }}=892773$ ) significant difference was between the energy received by the northern and the southern roofs, i.e. the effects of direct insolation apart from global and diffuse insolation can be detected.

Calculating with the most valuable southern roofs meeting the parameters defined by us, the total annual potential utilizable solar energy was $1239 \mathrm{MW}$. If we ignore the return of the costs and use all the roof parts to install solar panels the total solar energy would be 2'648 MW.

\section{Conclusion}

Based on the combined LiDAR hyperspectral database, roofs can be distinguished from other objects effectively in an automatic way in an urban environment resulting in a real database of the potentially suitable surfaces in the settlement. Selecting the most suitable roofs can also be automatized. The extent of the faults 
in identifying roofs (or missed roofs) can be tolerated. The amount of annual incoming radiation differs significantly according to the aspect. Southern roofs receive almost double the energy of that received by the northern ones.

As a whole, the method is suitable for calculating the extent of the potentially suitable roofs in the area of a whole city providing a firm basis for the optimal installation of urban renewable energy resources.

The value of the calculated potential solar energy shows well that roofs hide a significant energy resource that should be utilized even if the present work did not cover modifying factors like the influence of atmospheric attenuation by absorption, or shadowing and scattering effects.

\section{Acknowledgements}

Gergely Szabó's research was supported by the European Union and the State of Hungary, co-financed by the European Social Fund in the framework of TÁMOP 4.2.4. A/2-11-1-2012-0001 'National Excellence Program'.

The present work is supported by the TÁMOP-4.2.2.A-11/1/KONV-20120041 project. The project is co-financed by the European Union and the European Social Fund.

\section{References}

[1] EC, HORIZON 2020 in brief. The EU Framework Programme for Research \& Innovation, European Commission, Brussels (2014), 40 pp.

[2] Király, G., Domborzatmodellek elóállításához felhasználható forrásadatok összehasonlító vizsgálata (Comparing Source Databases Generating Digital Elevation Models), HUNDEM Conference 2004, Miskolc-Hungary.

[3] Liu, X., Airborne LiDAR for DEM generation: some critical issues. http://ppg.sagepub.com/content/32/1/31.short. In: Progress in Physical Geography, February 2008 vol. 32 no. 1, pp. 31-49.

[4] Király, G., Brolly, G., Burai, P., Tree Height and Species Estimation Methods for Airborne Laser Scanning in a Forest Reserve. In: Nicholas Coops, Mike Wulder (ed.): Full Proceedings of SilviLaser 2012: 12th International Conference on LiDAR Applications for Assessing Forest Ecosystems. 492 pp. Vancouver, Canada, 2012.09.16-2012.09.19. Vancouver: pp. 260-270.

[5] Mücke, W., Deák, B., Schroiff, A., Hollaus, M., Pfeifer, N., Detection of fallen trees in forested areas using small footprint airborne laser scanning data. In: Canadian Journal of Remote Sensing 39: Paper 10.5589/m13-013. (2013).

[6] Priestnall, G., Jaafar, J., Duncan, A., Extracting urban features from LiDAR digital surface models, In: Computers, Environment and Urban Systems, Volume 24, Issue 2, 31 March 2000, pp. 65-78.

[7] Yu, B., Liu, H., Wu, J., Hu, Y., Zhang, L., Automated derivation of urban building density information using airborne LiDAR data and object-based method, Landscape and Urban Planning 98 (2010) pp. 210-219. 
[8] Zhou, Q., Neumann, U., Complete residential urban area reconstruction from dense aerial LiDAR point clouds, Graphical Models 75 (2013) pp. 118-125.

[9] Mongus, D., Lukac, N., Zalik, B., Ground and building extraction from LiDAR data based on differential morphological profiles and locally fitted surfaces, ISPRS Journal of Photogrammetry and Remote Sensing (2014).

[10] Li, Y., Wu, H., An, R., Xu, H., He, Q., Xu, J., An improved building boundary extraction algorithm based on fusion of optical imagery and LiDAR data, Optik 124 (2013) pp. 5357-5362.

[11] Alexander, C., Skith-Voysey, S., Jarvis, C., Tansey, K., Integrating building footprints and LiDAR elevation data to classify roof structures and visualise buildings. Computers, Environment and Urban Systems 33 (2009), pp. 285-292.

[12] Lukac, N., Seme, S., Zlaus, D., Stumberger, G., Zalik, B., Buildings roofs photovoltaic potential assessment based on LiDAR (Light Detection And Ranging) data, Energy 66 (2014) pp. 598-609.

[13] Terra Scan User's Guide, https://www.terrasolid.com/download/tscan.pdf.

[14] ArcGIS Resources page, An overview of the Solar Radiation tools, http://resources.arcgis.com/en/help/main/10.1/index.html\#//009z000000t4 000000 .

[15] Lorup, E. J., IDRISI Tutorial on: www. http://web.pdx.edu/ nauna/ resources/IDRISI-tutorial.pdf. 